\title{
Designing a Sport Development Model in Iran's Free Trade Industrial Zones
}

\author{
${ }^{1}$ Amin Saberi ${ }^{*}{ }^{1}$ Masoumeh Kalateh Seifari, ${ }^{1}$ Morteza Dosti, ${ }^{1}$ Seyed Mohammad Hossein Razavi, \\ ${ }^{1}$ Farzam Farzan
}

${ }^{1}$ Department of Sport Management, Faculty of Sport Science, University of Mazandaran, Babolsar, Iran.

\begin{abstract}
Background. One of the most important elements of life are physical activity and sport: these are the basis of health during life. In order for society to benefit from the advantages of physical activity and sport, it is necessary to know the factors influencing this phenomenon. Objectives. The purpose of this paper is to design a sport development model in the free trade-industrial zones of Iran. Methods. The research was qualitative, and was done using the grounded theory approach and based on the systematic approach of Strauss and Corbin (1998). The geographic area of the research included seven free trade trade-industrial zones of Iran; the data collection tool was a semi-structured interview. Participants in the research were the sport authorities of Iran's free zone, sport officers, officers of the Ministry of Sport and Youth of free zones, staff members of the Ministry of Sport and Youth, and sport professors; interviews involved 22 informed persons. Results. The results of data coding showed that causal factors (individual, interpersonal, and structural) centrally affect sport development. Cultural, social, economic, political, technological, legal, and environmental factors were also selected as context and interventional factors. Development of management; development of space, equipment, and great sport events; cultural and social development; scientific and legal development; and development of financial resources were designated as strategies for the development of sport, which will also lead to economic, cultural, social, environmental, and political consequences. Conclusion. Given the positive outcomes for the development of sport, it can be useful as an effective tool in achieving the major goals of Iran's free trade-industrial zones.
\end{abstract}

KEY WORDS: Sport, Free Zones, Development, Grounded Theory Approach, Outcomes.

\section{INTRODUCTION}

Physical activity and sport are one of the most important elements of life. They are the basis of health during life and have benefits such as lowering the risk of cardiovascular diseases, high blood pressure, diabetes, and some types of cancers for the health of individuals (1). In this regard, in 2016 the World Health Organization stated that lack of physical inactivity is one of the four main causes of death in the world. It causes
3.2 million deaths annually in the world; about $60 \%$ of Iran's population is overweight: performing physical activity and sport are one of the ways to prevent obesity and overweight (2).The most important benefits of physical activity and sport are that they reduce physical and mental health problems and save on health care costs. Reducing the rate of crime and antisocial behaviors, reducing ethnic tensions,

*. Corresponding Author:

Amin Saberi

E-mail: aminsaberi2018@gmail.com 
increasing collective activities, increasing social participation, and increasing voluntarily activities are among other social benefits of sport (3). Inadequate physical activity has imposed significant health costs on communities. For example, in Britain, the economic cost of cardiovascular diseases is more than 30 billion pounds while for diabetes it is 9 billion pounds a year (4). Sport has the ability to create national pride and unity and is also a large and complex business (5). Sport, in addition to social benefits, has positive economic effects. In a case study, Duglio and Beltramo (2017) showed that for every euro spent by the government on a small sporting tour event, the economic return was estimated to be between 17.62 and 18.92 euros. This implies direct economic returns to the local community (6). However, mega sport events such as the Olympic Games, Asian Games, World Championships, etc. use considerable environmental resources that require all sport organizations and institutions in governing countries to take measures to avoid harming the environment (7).

In order for benefit individuals and society from health, economic, and social advantages of sport, it is necessary to know the factors influencing its development. A lot of research has been done in this regard, which will be discussed later. Pourranjbar and Zeytoonli (2017) showed that there is a relationship between perceptual and social factors such as positive knowledge and attitude, gaining physical well-being, mental health development, social interaction development, acquisition of sport skills and experience, leisure enrichment, environmental quality, service quality, equipment and sport sites, media and advertising, and social support with a degree of students' participation in public sport (8). Another study showed a significant relationship between participation in sport and gender; being young; being single; not having a child under two years of age; not smoking; and understanding the benefits of sporting activities such as being aware of health benefits and enjoying participation, fitness, socialization, and appearance (9). Mohammadi and Azizmalayeri (2016) introduced economic, social, facilities, management, individual and cultural factors as barriers to participation in sport (10). Turrin et al. (2016) pointed to the important role of designing sport facilities on championships as well as recreational sport activities (11). Another study carried out in Portugal showed that the number of athletes increase under certain conditions, such as population density, mortality rates, crime rates, increased sport managers and increased expenditure on culture and sport (12). Other research results showed that the decision to participate in sport and the frequency of sport participation were influenced by age, gender, socioeconomic status, and area of residence (13). Another research showed that variables such as sporting policies, sport personnel, sport budgets, sport plans, sport facilities, and financial support could be effective in sport development (14). Another research showed a statistically positive relationship between access to places and demographic variables, age, education, and socioeconomic variables (15). Farrell et al. (2013) showed that high level of physical inactivity is related to socioeconomic status. Education, household income, deprivation in local areas, access to physical recreations and sport facilities, local weather, and geography of the region are related with physical inactivity (16). Eime et al. (2013) conducted a review study and designed a conceptual model of health through physical activity and sport. In this model, interpersonal, intrapersonal, organizational, environmental, and political factors affect sport (17). Deniz and Yenel (2013) believe that performance measurements such as the selection of sport managers from among specialists, preparing plans of sport federations, the government's support for providing sport services, increasing the content and hours of physical education classes in academic courses, the cooperation of federations and clubs with schools are required to develop sport (18). Another study found that variables such as age, gender, health status, social status, education, income, rural or urban residence, place of birth, social status, employment status, level of self-control, and environmental characteristics were effective in developing sport (19). Luiz and Fadal (2011) stated that success of countries in sport is directly related to the economic resources available for sport: sport's performance in Africa, according to their research, is dependent on a range of socioeconomic factors (5). In another study, gender, customs, personal values, and cultural factors were found to be related to sport 
participation. Negative attitudes toward exercise, low level of awareness, lack of facilities were among the reasons for low participation in sport; and financial ability and encouragement of family members were known to be the main reasons to participate in sport (20). Sotiriadou et al. (2008) studied the processes of sport development in Australia, with the use of the theory of surveying three structures: they addressed the processes of attracting, preserving/transmitting, and cultivating. The results of the research showed that the process of development of each sporting sector requires financial and human inputs from different stakeholders. These stakeholders initiate sport development strategies for each process, and each process has different outlets for sport development (21).

A free trade zone is a geographic zone that is excluded from some of the current public regulations of the country by creating advantages such as tax exemptions and customs duties and exemptions from specific export and import regulations to attract foreign investment and modern technology to help develop the mainland. These zones have advantages such as currency earnings through exports, capital appreciation, reduced unemployment, local development, knowledge and technology transfer, increased skilled laborers, and a model for testing free trade at the national level (22). Free zones of Iran were created according to note 19 of the first socioeconomic plan of the Islamic Republic of Iran with the aim of attracting foreign capital and export development in order to achieve goals such as accelerating the implementation of infrastructure, development, economic growth, creation of employment, investing, and producing and exporting goods. Iran has seven free trade zones: Kish, Qeshm, Chabahar, Aras, Arvand, Anzali, and Maku. These are adjacent with land or sea borders to countries such as Turkey, Iraq, Russia, the United Arab Emirates, Oman, Pakistan, Afghanistan, Azerbaijan, Kuwait, and the Nakhchivan Autonomous Republic. Among the advantages and capacities specific to free zones in the field of sport are neighborhood with neighboring countries; climate variation; easy commute for foreigners; facilitating exports and imports; tax exemptions; facilitating the hosting of international competitions; the use of sport facilities of neighboring countries such as recruiting coach, professors, knowledge raising classes; and the use of judges and international elite athletes who are less used for the development of sport and free zones. On the other hand, each free zone will pursue different sport goals with the mainland, including attracting tourists, creating employment, introducing the region, etc. In order to achieve these goals, there is a need for new laws, structures, methods, and processes so as to eliminate administrative bureaucracies and legal barriers.

The sport of free zones is less attended to by thinkers and scholars in research related to sport development: such research is being conducted for the first time in Iran. Obviously, sport-like any other phenomenon-is affected by many factors. These factors vary in each region of the world according to the conditions prevailing in that region. Since the development of sport in the free zones is no exception, it is necessary to identify the factors influencing the sport of free zones. In accordance with the conditions of free zones and utilizing practical methods, these factors should be presented in the form of a model in order to serve as a basis for planning and policy making by officials and authorities of free trade industrial zones of Iran.

\section{MATERIALS AND METHODS}

Research design. This research was conducted using a qualitative approach based on the grounded theory approach. In general, there are three methods in the grounded theory approach: in this research, the systematic design in the grounded theory was used by Strauss \& Corbin (1998). In this method, the information analysis steps are created by open, axial, and selective coding, and the development of a logical paradigm or a visual representation of the theory. In the first step, open coding was performed. Theorists of the grounded theory examine initial forms of information classes about the phenomenon being examined by the division of information. Second step was axial coding. The theorist of the grounded theory chooses a class of open codes, places it in the process center (as an axial phenomenon), and then connects other classes to it. Other classes include: causal conditions (factors affecting the main phenomenon), strategies (actions in response to the axial phenomenon), context and interventional conditions (specific and general situation factors 
affecting strategies), and outcomes (results of using strategies). This step involves designing a diagram that illustrates the relationship between causal conditions, strategies, context and interventions, and outcomes. The third step was selective encoding. The theorist of the grounded theory creates a theory in relation to classifications in an axial coding model. At the basic level, this theory provides an abstract explanation for the process under study (23).

Participants. The statistical population of this study was experts in the field of sport in the free zones of Iran: it included sport professors, officials and staff experts of sport federations of the Ministry of Sport and Youth, as well as sport managers of free zones of Iran who were selected using purposive sampling by the snowball method. Sample size in qualitative research is synonymous with the completion of data or the saturation of data. In this research, from the $17^{\text {th }}$ interview onwards, theoretical saturation of data was obtained: still, 22 participants were interviewed for more certainty.

Data collection tool. Data collection tool in this research was premised on a semi-structured interview. Interviews began with generic and simple questions and went into more detailed ones. In order to attract more participation and cooperation of the people studied, they were telephoned beforehand to determine the appropriate time. All interviews were recorded with the consent of the participants and data analysis was carried out immediately after each interview. The duration of data collection was thirteen months: each interview lasted from 30 to 70 minutes based on the willingness of the interviewee.

Measurement. The overall purpose of the present study is to explain and design the sport development model in Iran's free zones. In order to achieve this goal, the following questions were raised: What are the causal conditions of the model of sport development in the free zones of Iran?
What is the axial phenomenon in designing the model of sport development in the free zones of Iran? What are the strategies for sport development in the free zones of Iran? What are the effective intervention conditions for the sport development model in Iran's free zones? What are the dominant context factors affecting sport development model in Iran's free zones? What are the outcomes of the sport development model in Iran's free zones? In order to determine the trustworthiness of the data, techniques of triangulation, self-monitoring of the researcher, and member checks were used. In the triangulation technique, interview questions in the research design were dealt with through two or more practical questions in a way that the interested phenomenon could be examined from different aspects rather than a single question. During the coding, the codes from the interviews were compared with the literature of the research. The use of member checks techniques is another way of increasing credibility: data analyses and their results were given to respondents in order to make them aware of their reaction in the step of reporting writings. The research self-monitoring technique during the process of data collection and data analysis is another method that could increase credibility: the researcher repeatedly revised the codes. In the following, the final model and coding were given to three interviewees, their views were applied, and they confirmed the overall model of the research.

\section{RESULTS}

The educational degree of about 0.96 of the interviewees were graduate students and higher. About 0.91 of the interviewees were male; the place of employment of about 0.41 of the interviewees was the Ministry of Sport and the Iranian sport federations. Other characteristics of the participants in this study are listed in Tables 1 .

Table1: Characteristics of interviewees

\begin{tabular}{ccccccc}
\hline Index & \multicolumn{3}{c}{ Sex } & \multicolumn{3}{c}{ Employment place } \\
\cline { 2 - 7 } Variable & Man & Woman & Total & University & Free Zone & $\begin{array}{c}\text { Ministry of Sport, and } \\
\text { Sport federations }\end{array}$ \\
\hline Frequency & 20 & 2 & 22 & 5 & 8 & 9 \\
Frequency percentage & $0 / 91$ &.$/ 09$ & $0 / 100$ & $0 / 23$ & $0 / 36$ & $0 / 41$ \\
\hline
\end{tabular}

The research questions were responded by performing the data collection and analysis process in the open, axial, and selective coding steps: the final sport development model in the 
free trade industrial zones of Iran was based on this compilation process. Using the systematic model of Strauss and Corbin (1998), a total of 585 open codes were obtained from the analysis of the 22 interviews. All open codes were categorized into 18 categories and 6 propositions (causal factors, axial phenomenon, intervening factors and context factors, strategies, and outcomes).

In this model, sport development was selected as an axial phenomenon. Based on the systematic model of Strauss and Corbin (1998), causal factors created and developed axial phenomenon. According to the participants in this research, causal factors included individual, interpersonal, and structural factors that affect the development of sport. Context and intervention factors provide the context and the field of sport development. In this research, economic, cultural, social, and environmental were selected as intervention factors and technological, political, international, and legal were selected as context factors. The next category is strategies: these are based on actions and reactions to control, manage, and deal with the phenomenon. Management development, space development, equipment and sporting events, cultural and social development, scientific and legal development, and finally the development of financial resources were selected as sport development strategies in the free trade zones of Iran. The last category is outcomes. Outcomes occur due to strategies and are the result of actions and reactions. These strategies also have economic, cultural, social, environmental, and political implications. These factors are shown in Figure 1 in the form of the final model of the research.

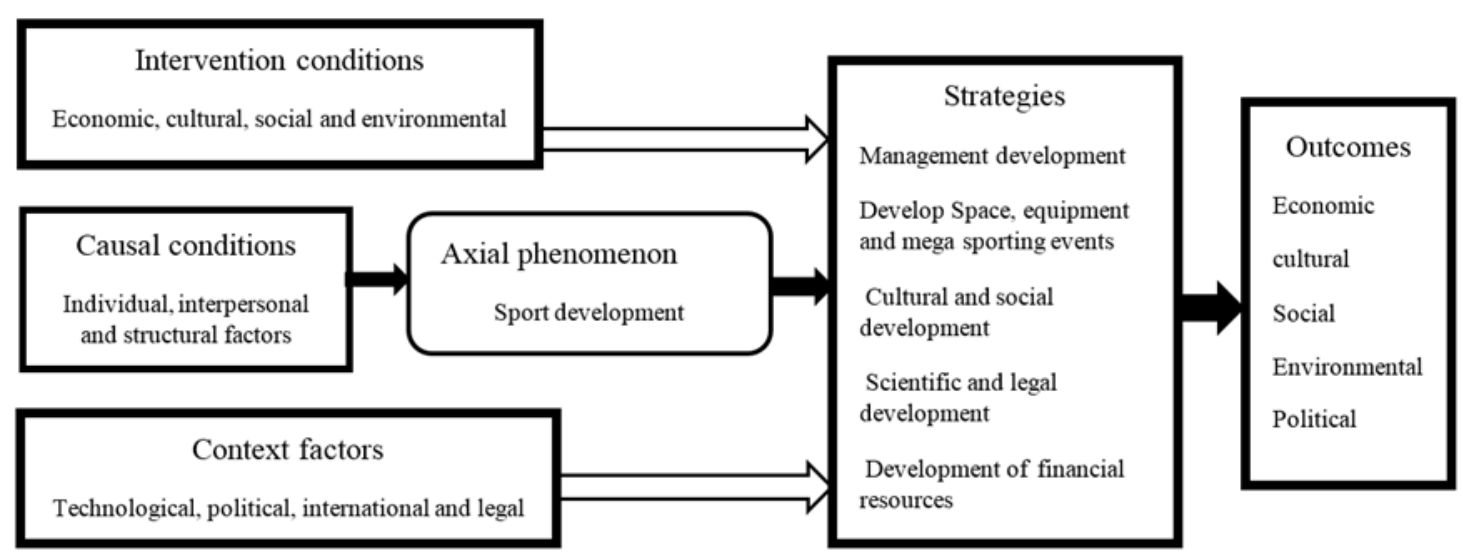

Figure 1. Model sport development in Iran's Free Trade Industrial Zones.

Since the significance level is zero (it is lower than 0.05), it can be concluded that despite the difference in the ranking average of the weaknesses in sport for all, this difference is not significant and the weaknesses have a similar impact on the sport for all policy-making process.

\section{DISCUSSION}

Using the systematic theory of Strauss and Corbin (1998), sport development was chosen as an axial phenomenon. According to this theory, causal factors cause axial phenomenon. According to the participants in this research, the causal factors that lead to sport development include individual factors (age, gender, marital status, education, occupation, physical conditions, and mental conditions), interpersonal factors (parental conditions, social support) and structural factors (previous experiences, being employed, lack of time, residential conditions, sport conditions, and having family responsibility). People, for various reasons such as the advice of doctors, maintain and develop health, gain many benefits from physical activity, medal acquisition, fame, etc., face sport. Lack of physical activity has negative consequences on health, including the occurrence of cardiovascular diseases, blood pressure, obesity, etc. Parents, on the other hand, use sport as an effective tool in child rearing: those with who have an 
understanding of the importance of sport or have a history of sporting themselves direct their children to sport. Having a child, lack of time, job, and insufficient income have act as barriers to the sporting tendency. Therefore, planners and authorities must identify these barriers and provide guidelines such as setting up sport classes for mothers and children, sport subsidies, and other programs so that everyone has the opportunity to do sport.

The intervening factors are general conditions which affect strategies. These factors, from the perspective of participants in this study, include cultural, social, economic, and environmental context that can facilitate or impede sport development. Success in international fields and the generalization of sport requires large expenditures: employment status, income level, economic growth, and inflation rate also effect sport development. On the other hand, having economic problems in families causes families to reduce their sport expenses or to quit sport and the world of championship due to lack of financial ability. Among social indicators, the level of security is especially important for women and lowincome groups. The level of trust between people, the level of trust between people and authorities, and the level of trust between people and sport organizations are among the factors influencing the development of sport in the free zones. If the level of trust is low, the possibility of the activity of professionals and practitioners of sport becomes difficult. Other intervening factors are cultural factors. In a society where sport are regarded valuable and mobility is a part of people's lives, sport development will be faster. As Farrell et al. (2013) stated, in order to reduce the prevalence of physical inactivity, cultural and financial barriers ought to be overcome (16). Therefore, cultural and financial barriers in the free zones that affect the development of sport should be identified and the necessary measures to eliminate these barriers should be taken. The environment is one of the other factors affecting the development of sport in the free zones. Some of the free zones of Iran, due to climatic conditions (such as dust haze, extreme heat, etc.) are not suitable for sporting activities. Therefore, it is necessary that the policy makers of each zone plan in accordance with the climatic and geographical conditions to make optimal use of available capacities so as to develop sport.

Based on the systematic approach of the grounded theory, context factors are specific conditions that affect strategies. According to the participants in this research, context factors include political, international, technological, and legal context. Political factors include attitudes of statesmen and the politicization of sport. Throughout history, governments have always used sport to achieve their political goals. Governments play a direct role in sport through actions such as resource distribution, large-scale policymaking, and selection of authorities of sport. Free zones are full representatives of the government within a specific and confined geographical zone and this confined geographical zone is managed by executive directors. Indeed, free zones as a local government play a major role in the development of sport, and, as a result, executive directors and board members of each zone play the most important role in the sport development of zones. The appointment and modification of sport managers of zones, officials of sport boards, and the presence of politicians in the body of sport are one of the signs of the politicization sport in the free zones. According to the participants in the study, political context is one of the influential factors in the field of sport. Another environmentally effective factor in the field of sport is technological context. New sporting technologies, such as diverse kinds of advanced laboratory equipment, devices and tools for talent scouting, and software related to health and exercise affect sport development. Therefore, new technologies must be introduced, developed, and used because in today's world, where competition is in hundredths of seconds, countries that have superior technologies gain more success in the field of sport. Based on the view of the participants in this research, legal context is another context factor that affects sport development strategies in the free zones. 
Participants in the research believe that existing laws need to be revised and that there are also legal gaps.

Participants in this study believe that social development, scientific and legal development, development of space and equipment and large sport events, development of financial resources, development of international relations, and development of managerial resources are among the most important strategies for developing sport in the free zones. The development of public infrastructure is of particular importance among social indicators. Without an airport, accommodation and nutrition centers, communication paths, internet etc., hosting competitions, dispatching teams, presence of sport professionals, and other things would encounter problems: it is likely that lack of adequate infrastructure can act as a major obstacle in the development of sport. Among other social indicators is the development of social justice. Social justice is one of the most important demands in any civil society, which is also of great importance in the field of sport. Deprived, disabled, and lowincome classes, like all other classes of the population, should have equal sporting opportunities. In other words, the general public should have fair access to sport facilities and sites in order to do sport activities. The distribution of sport facilities is often concentrated and in a specific area, and not everyone has the opportunity to do sport fairly. Sport policymakers must provide the conditions in a way that ensures social justice in the field of sport and all capacities are used. In addition to administering justice in the distribution of places, there must be opportunities equal to each other regardless of ethnicity, gender, social class, area of residence, and disability in the selection of team members, discovery of talents, and sport management in each region. Also, the development of sporting culture among residents of free zones by promoting the useful effects of sport on individuals and ultimately increasing their physical literacy and the presence of officials in sport programs are among the strategies that can influence the development of sport in the free zones of Iran.
Scientific and legal development are among other sport development strategies for Iran's free trade-industrial zones. The use of traditional methods in the field of sport will not get us anywhere. New scientific methods of sport development should be used. Legal development is among other strategies for sport development for Iran's free trade industrial zones. According to the participants in this study, the development of sport requires attention of rules to support champions and athletes. Additionally, criterion-centered and reduction of the level of relationship-centered in sport are legal development strategies.

Space, equipment, and events development are other strategies for the development of sport in the free trade industrial zones of Iran. The foundation for sport development is the development of space and equipment because an athlete needs a sport site with quality and easy access to practice in the first place. In addition to having appropriate sport sites, the need for appropriate sport equipment is also a necessity. The performance of sport champions depends to a great extent on suitable and high-quality sport equipment and facilities. Additionally, in deprived areas, sporting equipment is also needed: the provision of sport facilities can help boost sport by providing sport equipment in those areas. Also, holding major sporting events is also among other strategies for sport development because the holding of these events leads to the introduction of sport and motivation among champions, athletes, and ordinary people.

Among other strategies for the development of sport from the point of view of the participants in this research is sport financial source. Financial resources act as fuel in the sport system and the wheel of sport cannot move without the supply of this source. These resources should also be injected timely and on the basis of priority and justice.

Development of international relations is among other strategies for the development of sport in the free zones. Establishment of free zones on the borders of the country and their proximity to neighboring countries or high seas have created a unique opportunity for these regions: these can be used with careful planning 
of these capacities in the sport sector. Some of the neighboring countries of the free zones, such as Turkey, have a high level of sport: by increasing sport interactions, such as holding joint events, exchanging coaches and athletes, their successful experiences in the field of sport can be used.

The development of managerial resources is among other strategies for sport development in the free trade industrial zones of Iran. If all the factors and conditions necessary for sport development are available, but there is no expert and capable human resources, there will be no result except wastage of resources. Therefore, there should be managers capable in the field of sport in the free trade industrial zones of Iran to manage the resources and use the management science to mobilize all the capacities: meritocracy should be dominant to achieve this goal. Optimally performing management tasks, managerial stability, human resource empowerment, stakeholder interaction, reduction of bureaucracy and improvement and promotion of the status of sport in the organizational structure of the free zones are among other managerial factors that can accelerate sport development in the free trade industrial zones of Iran.

From the perspective of participants in this study, the outcomes of sport development in free zones include political, economic, sociocultural, and environmental consequences. Sociocultural outcomes of sport development in free zones include the development of general health, the beneficial use of leisure time, the reduction of antisocial behavior, and change in the lifestyles of residents of free zones: these add mobility in these zones to people's lives and effect economic development by reducing treatments costs and increasing labor productivity, attracting tourists, and creating jobs. On the other hand, the role of sport in consolidating friendly relations with neighboring countries and other countries is not latent to anyone. Other consequences of sport development include environmental consequences. From the point of view of the participants in this study, sport and environment have reciprocal effects: in some cases, sport effects environmental protection by reducing the use of motor vehicles and the use of clean energy. In some cases, it negatively effects the environment by the production of waste, increased use of plastic containers, cutting trees for the construction of sport facilities, creating noise pollution and poor management, and the loss of energy in sporting facilities.

\section{CONCLUSION}

Based on the analysis of participants' data in this study, sport development in the free zones of Iran is a complex process that is affected by a variety of factors. Therefore, knowing these factors helps free zone managers to plan for sport. Given that individual factors influence sport development, demographic information of people in the free zones of Iran, including age, gender, marital status, etc. should be used in order to plan sport. On the other hand, interpersonal factors also influence sport development so plans need to be provided for increasing social protection. Finally, structural factors, such as access to sites, quality of facilities, etc. also play a role in sport development: planning must be done in order to improve and increase the efficiency of existing sport sites, and the views of the participants in this research should be considered in the construction of new sport sites. As already mentioned, a lot of underlying and intervening factors affect the strategies for sport development. Therefore, senior officials of the Organization of Iran Free Zones should pay attention to the role of these factors in formulating sport development policies and provide conditions for sport development. Strategies for sport development from the point of view of the participants in this study were provided: hence, given the existence of specific rules for free zones, authorities of free zones can take measures in order to develop sport. Finally, from the point of view of the participants in this research, sport development has social, economic, cultural, political, and environmental consequences that are in many cases positive and in line with the main goals of establishing free trade industrial zones of Iran. But in the 
environmental sector, measures should be taken to minimize these negative environmental outcomes and to use the capacity of sport to achieve the major goals of the creation of these zones.

The researcher in this research faced restrictions owing to the sport structure of the country. This includes a short history of free zones in Iran; different cultural, social, economic, and geographical conditions of the free zones of Iran with each other; strong dependence of free zones of Iran on the mainland; and lack of clarity on the position of sport in the free zones of Iran. Therefore, it is suggested to other researchers to investigate the economic, social, and political consequences of sport development in Iran's free zones.

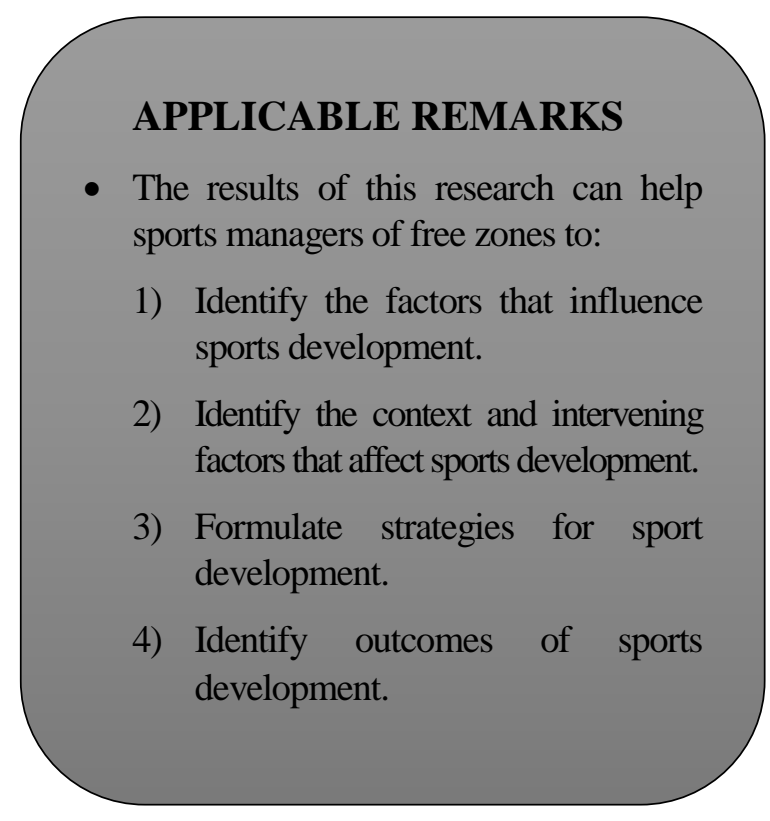

\section{REFERENCES}

1. World Health Organization. Physical activity strategy for the WHO European Region 2016-2025. Organ Mund la Salud. 2015; (September 2015):1.

2. www.who.int. http://www.who.int/mediacentre/factsheets/fs311/en/. 2018.

3. Taylor P, Davies L, Wells P, Gilbertson J, Tayleur W, Christy E, et al. A review of the Social Impacts of Culture and Sport. 2015; (March):1-136.

4. Cox S. Game of life: How sport and recreaction can help make us healthier,happier \&richer [Internet]. Sport and Recreation Alliance.; 2012. Available from: sportandrecreation.org.uk

5. Luiz J, Fadal R. An economic analysis of sports performance in Africa. Int J Soc Econ. 2011;38 (10):869-83.

6. Duglio S, Beltramo R. Estimating the economic impacts of a small-scale sport tourism event: The case of the ItaloSwiss mountain trail CollonTrek. Sustain. 2017;9 (3).

7. Brar RS, Pathak A. Sports and Environment 1. Sopaan - II. 2016;1 (1):7-11.

8. Pourranjbar M, Zeytoonli AH. Describing Factors Affecting Participation of Students in Public Sport. Int J Sci Study. 2017;5 (8):344-8.

9. Oliveira-Brochado A, Quelhas Brito P, Oliveira-Brochado F. Correlates of adults' participation in sport and frequency of sport. Sci Sports. 2017;32 (6):355-63.

10. Mohammadi M, Azizmalayeri K. The Study of factor Affecting sport participation faculty and staff of the university of malayer city from their perspective. Soc Sci 11 (16). 2016;3669-975.

11. Turrin M, Yang D, D’Aquilio A, Sileryte R, Sun Y. Computational Design for Sport Buildings. In: Procedia Engineering. 2016. p. 878-83.

12. Teixeira MRC, Ribeiro TMP. Sport policy and sports development: Study of demographic, organizational, financial and political dimensions to the local level in Portugal. Open Sports Sci J. 2016 ;9 (Suppl-1, M4):26-34.

13. Eime RM, Harvey JT, Charity MJ, Casey MM, Westerbeek H, Payne WR. Age profiles of sport participants. BMC Sports Sci Med Rehabil. 2016;8 (6):1-10.

14. Yazid LI. Sport development; The Nigerian way : A review. Int J Phys Educ Sport Heal IJPESH. 2015;1 (4):20-4.

15. Downward P, Lera-López F, Rasciute S. The correlates of sports participation in Europe. Eur J Sport Sci. 2014;14 (6):592-602.

16. Farrell L, Hollingsworth B, Propper C, Shields M a. The Socioeconomic Gradient in Physical Inactivity in England. C Work Pap Ser. 2013;13 (311):1-33.

17. Eime RM, Young JA, Harvey JT, Charity MJ, Payne WR. A systematic review of the psychological and social benefits of participation in sport for adults: informing development of a conceptual model of health through sport. Int J Behav Nutr Phys Act. 2013;10:1-14.

18. Deniz S, Yenel F. The Structural Analysis of Physical Education and Sports System in The Turkish Republic of Northern Cyprus. Procedia - Soc Behav Sci. 2013;89:772-80.

19. Erker RS, Ličen S. Review of physical activity and predictors and population groupsat risk of poor health. 2012. 
20. Nambaka JE, Kamau J, Amusa LO, Goon DT, Andanje M. Factors influencing participation in physical exercise by the elderly in Eldoret West District, Kenya. African J Phys Heal Educ Recreat Danc. 2011;17 (3):462-72.

21. Sotiriadou K, Shilbury D, Quick S. The Attraction, Retention/Transition, and Nurturing Process of Sport Development: Some Australian Evidence. J Sport Manag. 2008;22:247-72.

22. Malhotra S. Free Trade Zones: Characteristics and Tenant Behaviour. Carleton University; 2007.

23. Creswell JW. Educational research: Planning, conducting, and evaluating quantitative and qualitative research. Boston: Edwards Brothers. Inc; 2012. 